\title{
Autocontingencies: Factors underlying control of operant baselines by compound tone/shock/no-shock contingencies
}

\author{
HANK DAVIS, DONALD SHATTUCK, and JANET WRIGHT \\ University of Guelph, Ontario NIG 2 Wl, Canada
}

\begin{abstract}
Previous research has shown that postshock acceleration of baseline responding, which normally results from exposure to a shock/no-shock autocontingency, is eliminated when a suppressive tone-shock contingency is simultaneously presented (Davis, Memmott, \& Hurwitz, 1975). Three experiments were performed to explore this inability to produce joint suppressive/ accelerative control by compound tone-shock and shock/no-shock contingencies. Progressively degrading the tone-shock contingency in Experiment 1 maintained conditioned suppression and resulted in asymptotic levels of postshock acceleration in all degraded groups. Evidence for accelerative control by the autocontingency was also recorded in a control group that received a totally reliable tone-shock relation. Experiments 2 and 3 pursued this latter finding, which is in direct conflict with our earlier results. The appearance of joint suppressive/ accelerative control by tone-shock and shock/no-shock contingencies appears to be related to the number of shock trials given per session; moreover, relatively small differences in trial density (e.g., three trials per $22.5 \mathrm{~min}$ vs. three trials per $30 \mathrm{~min}$ ) are critical to establishing joint autocontingency control. The importance of shock rate is discussed with regard to the relative waiting time hypothesis, an alternative model of Pavlovian control, as well as to previously reported conditioning failures involving compound suppressive/accelerative procedures.
\end{abstract}

The effects of the conditioned suppression procedure are widely known: a stimulus that precedes the delivery of unavoidable shock suppresses the rate of baseline operant behavior (Davis, 1968; Estes \& Skinner, 1941). Variations of this procedure, in which inhibitory arrangements between signal and shock are programmed, have typically resulted in accelerated baseline responding during presentations of the conditioned stimulus (CS-) (Davis \& Mclntire, 1969; Hammond, 1966).

It is also possible to produce conditioned acceleration of baseline responding without the use of a CS. Davis, Memmott, and Hurwitz (1975) demonstrated that the offset of shock itself could reliably occasion periods of accelerated baseline responding if shock signaled periods free from subsequent shock. This procedure, under which a shock/no-shock contingency prevailed, was termed an "autocontingency." It resulted in postshock periods of baseline acceleration, in a manner that suggested inhibitory Pavlovian control or discrimination of shock-free periods.

This research was supported by Grant $A_{1}, 0673$ from the Natural Science and Engineering Research Council of Canada. A portion of these data was presented at the November 1978 meeting of the Psychonomic Society. The authors thank Herb Jenkins, John Staddon, Barbara Herring, John Memmott, Thom Herrmann, and Harry Hurwitz for their thoughtful criticisms. Reprints may be obtained from the first author at the Department of Psychology, University of Guelph, Guelph, Ontario N1G 2W1, Canada. D. Shattuck is now at McMaster University. J. Wright is now at the University of Manitoba.
These findings have been replicated, and behavioral control by autocontingencies appears to be a reliable and powerful phenomenon (e.g., Davis, Herrmann, MacFadden, \& Ellen, 1977; Davis \& MacFadden, 1978). Nevertheless, one puzzling aspect of our results has consistently appeared. Behavioral control by a shock/no-shock autocontingency has not occurred when shocks were signaled under a traditional tone-shock contingency. For example, Davis et al. (1975) reported that groups of rats that received unsignaled shock deliveries separated by a minimum 3-min interval showed accelerated baseline responding immediately following each shock offset. However, subjects for whom each shock delivery was signaled under a conditioned suppression procedure showed no postshock acceleration, even though the autocontingency was present. In short, suppressive control by a tone-shock contingency appears to preclude accelerative control by a shock/no-shock autocontingency.

\section{EXPERIMENT 1}

Experiment 1 was performed to explore the extent of tone-shock dominance over behavioral control by a simultaneously programmed shock/no-shock autocontingency. Our previous results indicated that autocontingency control did not occur when each shock was signaled. What would happen if the toneshock contingency were systematically degraded in 
the presence of the autocontingency? Would autocontingency control (i.e., postshock acceleration) emerge at some intermediate level of tone-shock contingency degradation? Would a continuum of autocontingency control occur, depending upon the degree to which the tone-shock relation was degraded?

To examine these and related questions, we exposed five groups of rats to simultaneous tone-shock and shock/no-shock autocontingencies; however, the tone-shock relation was progressively degraded across groups. In the first group, all shocks were signaled, as they had been in our original experiments (Davis \& MacFadden, 1978; Davis et al., 1975). In intermediate groups, only $66 \%, 50 \%$, and $33 \%$ of the shocks were signaled during each session. The remaining group of subjects received unsignaled shock in the presence of the autocontingency.

In order to degrade the tone-shock contingency, we reduced the number of CSs per session while holding shock frequency constant. This procedure is arguably the most appropriate technique to degrade the tone-shock contingency, since it directly addresses the redundancy between tone-shock and shock/noshock autocontingencies. A fully reliable tone-shock contingency predicts not only the occurrence of shock $[p(U S / C S)=1]$, but also the absence of shock under its no-tone/no-shock logical obverse $[p(\overline{\mathrm{US}} / \overline{\mathrm{CS}})$ $=1]$. It is this negative aspect of the tone-shock contingency that renders the shock/no-shock autocontingency redundant and conceivably underlies blockage of autocontingency control. By degrading $p(\overline{U S} /$ $\overline{\mathrm{CS}}$ ) while maintaining a totally reliable tone-shock relation, the present procedure may retain conditioned suppression, while sufficiently reducing noshock redundancy to allow for simultaneous behavioral control by the autocontingency.

\section{Method}

Subjects. Thirty experimentally naive male Long-Evans hooded rats, about 120 days old, were reduced to approximately $80 \%$ of their free-feeding weights. They were housed in individual cages under a 12-h light-dark cycle and had continuous access to water. Deprivation weights were maintained by the provision of supplementary food at the end of each experimental session.

Apparatus. The subjects were run during the light cycle in commercially available operant test chambers (Campden Instrument Co.) housed in sound-attenuated boxes. Each chamber was $24.5 \times$ $23 \times 20.5 \mathrm{~cm}$. A food hopper was located midway between two retractable levers situated on either side of the front panel. Only the left lever was operable. Forty-five-milligram Noyes pellets served as reinforcers. The floor of each chamber consisted of 16 stainless steel grids $.9 \mathrm{~cm}$ in diameter and $.9 \mathrm{~cm}$ apart, edge to edge. A constant-current shock generator (Campden Instrument Co.) was used to deliver 1-sec .6-mA scrambled shock to the grids. The CSs were provided by Mallory sonalerts located in the roof of each chamber. Each CS was a 1-min 90-dB (re .0002 dynes $/ \mathrm{cm}^{2}$ ) tone, with a frequency of $2,950 \mathrm{~Hz} \pm 5 \%$. Extraneous sounds were masked by white noise from a speaker in the ceiling of the room that housed the sound-attenuated boxes and by the circulation fans in each chamber.

Procedure. Experimental treatment consisted of three phases. In Phase 1, the animals were trained to leverpress for food on a continuous reinforcement schedule. They were then exposed to variable interval (VI) schedules, the interval being gradually increased until a stable base rate was obtained, in 45-minute sessions, on a VI 30-sec schedule. This schedule had a minimum of 10 and a maximum of $86 \mathrm{sec}$ between availability of reinforcers. Baseline training continued for approximately $\mathbf{4 0}$ sessions.

At the completion of baseline training, the subjects were matched according to response rate and assigned to one of five groups with six animals per group. Phase 2 consisted of offbaseline training for 14 sessions, during which the response lever was withdrawn and food reinforcement was withheld. During this phase, the tone-shock (CS-US) relationships assigned to each group were introduced. When a CS was scheduled, it began 1 min prior to the shock US. Each group received six shocks per session. Group 6 received six CSs per session; Group 4 received four CSs per session; Groups 3 and 2 received 3 and 2 CSs, respectively, and Group 0 had no CSs programmed during the session. The selection of which shocks were to be signaled in Groups 2, 3, and 4 varied randomly each day. Thus, each succeeding group had fewer CSs and, therefore, fewer shocks predicted per session, although $p(U S / C S)$ remained fixed at 1.00 . This procedure systematically reduced the dependability of the tone-shock contingency, beginning with one that predicted all USs in Group 6 and ending with the absence of a tone-shock contingency in Group 0 . All rats received the same autocontingency, consisting of a minimum 3-min interval between shocks, which were otherwise delivered randomly.

Phase 3 consisted of the reintroduction of the VI 30-sec and leverpress baseline, in conjunction with tone and shock occurrences, as originated in Phase 2. Phase 3 continued for $\mathbf{5 0}$ sessions. Three subjects, one from each of Groups 3, 2, and 0 , failed to show sufficient recovery of baseline responding and were excluded from subsequent analysis. An equal sample size was maintained by randomly dropping one animal from Groups 6 and 4, thereby leaving five subjects per group.

\section{Results}

Baseline responding. Following matching, all groups had the same Phase 1 mean base rate of 57 responses/min, so that it was possible to make direct comparisons of baseline responding among groups. The mean baseline response rates obtained for each group during the final five sessions of Phase 3 are shown in Table 1 . Base rate computations excluded the $1 \mathrm{~min}$ immediately before and after each shock. The analysis of these rates indicated a significant difference between treatments $[F(4,20)=$ $6.7, p<.001]$. A Newman-Keuls analysis indicated that the baseline of Group 6 was significantly higher than that of all other groups $(p<.01)$, and there were no other significant differences in group baselines.

Table 1

Mean Data Obtained During Final Five Sessions of Phase 3

\begin{tabular}{|c|c|c|c|c|}
\hline \multirow{2}{*}{$\begin{array}{c}\text { Treatment } \\
\text { Group }\end{array}$} & \multirow{2}{*}{$\begin{array}{l}\text { Baseline } \\
\text { Responses } \\
\text { per Minute }\end{array}$} & \multicolumn{2}{|c|}{ Preshock Ratio } & \multirow{2}{*}{$\begin{array}{c}\text { Postshock } \\
\text { Ratio }\end{array}$} \\
\hline & & Signaled & Unsignaled & \\
\hline 6 & 20.4 & .010 & & .647 \\
\hline 4 & 4.9 & .026 & .438 & .840 \\
\hline 3 & 3.3 & .082 & .390 & .884 \\
\hline 2 & 1.5 & .193 & .511 & .878 \\
\hline 0 & 1.5 & & .528 & .888 \\
\hline
\end{tabular}

Note-Group designations refer to number of CSs presented per session. 
Conditioned suppression. The ratio $\mathrm{A} /(\mathrm{A}+\mathrm{B})$ was used to determine the degree of suppression during the CS. The base rate discussed in the previous section served as $B$, and the response rate occurring during the CS minute served as $A$. A decrease in response rate during period $A$ relative to the $B$ rate would be reflected in a ratio of less than .5. Data analyses are based upon the mean responses from the final five sessions in Phase 3.

The ratios obtained during the preshock CS are given in Table 1. This table also presents ratios obtained in the preshock minute for Groups 4, 3, 2, and 0 on those trials when no CS preceded shock. There was an obvious reduction in response rate (i.e., conditioned suppression) on those preshock minutes when a tone actually occurred. In contrast, responding was relatively unchanged in the minute preceding shock when a tone did not occur. An analysis of variance was performed on the preshock ratios of Groups 2,3 , and 4, using sessions, groups, and presence of the CS as variables. The analysis revealed a significant main effect for CS presence $[F(1,12)=15.6, p<$ .01] but no differences attributable to treatment group $[F(2,12)=2.6, p>.25]$ or sessions $[F(4,48)=$ $2.8, \mathrm{p}>.15]$. No interactions were significant. A separate analysis of the nonsignaled ratios for Groups 0, 2, 3, and 4 showed no differences between groups $[F(3,16)=.86, p>.4]$.

A similar analysis of the signaled ratios for Groups $6,4,3$, and 2 , however, did reveal such a difference $[F(3,16)=4.0, p<.05]$, indicating that the groups varied in their degree of suppression to the CS, as reflected in the preshock ratios. Because the present situation is somewhat unusual in that the manipulations may have had their primary effect on the baselines rather than on the CS periods, it is possible that the present ratio difference may have been largely dependent on group differences in baseline rate. To test this possibility, we performed a supplemental analysis of the responses made during the CS, without regard to baseline rates. This analysis revealed no differences between groups $[F(3,16)=.58, p>.6]$, indicating that responding in all groups was suppressed to about the same level.

Shock/no-shock autocontingency. The shock/noshock autocontingency was based upon a minimum 3-min intershock interval. A conventional A/(A + B) ratio was used to determine whether this inhibitory contingency was effective in controlling behavior. The mean number of responses in the minute following shock served as A, while B was based upon response rate during the intershock interval, excluding the minute before each US. In contrast to suppression ratios, effective autocontingency control is shown by an increase in responding during period $\mathbf{A}$ relative to period $B$, and a ratio that exceeds .5 . The postshock ratio values obtained for each group during the final five sessions are summarized in Table 1.

The autocontingency was effective in controlling the postshock responding of Groups 4, 3, 2, and 0 , all of which showed high ratio values. These values did not differ from each other. Moreover, Groups 2, 3 , and 4 were analyzed to determine if the accelerative effect of shock was affected by whether or not the shock had been preceded by a CS. An analysis of variance that also used treatment groups and sessions as main effects revealed no significant differences between signaled vs. unsignaled postshock ratios $[F(1,12)=.33, p>.5]$, and no other significant main effects or interactions. Thus, the accelerative effect of the autocontingency on a particular trial did not depend upon whether or not the shock was signaled.

The mean postshock ratio for Group 6 was .64, considerably less than that of the other four groups, thereby resulting in a significant treatment difference $[F(4,20)=8.4, p<.001]$. A Newman-Keuls analysis indicated that the postshock ratio of Group 6 was lower than that of all other groups $(p<.01)$, but no further differences in group ratios. Thus, the presence of a totally reliable tone-shock contingency appeared to reduce the level of autocontingency control. A postshock ratio of .64, however, is still higher than a "no effect" value approximating .50, which has previously been obtained under these conditions. To determine whether the .64 ratio value indicates a significantly accelerated response rate during the minute following shock, we compared response rates obtained during the postshock minute in the final five sessions with response rates obtained in period $B$ (baseline). This analysis used the data from all six subjects in Group 6 since there were no subjects under this condition that exhibited a suppressed baseline. The analysis revealed a difference between the two means $[\mathrm{t}(5)=2.98, \mathrm{p}<.05]$, thus indicating that the completely reliable tone-shock contingency in Group 6 reduced, but did not eliminate accelerative control by the autocontingency. The uniformity of autocontingency control in the last four groups seems to suggest that any degradation in the reliability of the tone-shock contingency, at least within the range tested, resulted in maximal behavioral control by the autocontingency.

An analysis was performed on the postshock acceleration ratios obtained across trials, in order to determine whether control exerted by the autocontingency remained constant within a session. As suggested in Figure 1, postshock ratio values showed a pronounced within-session change $[F(5,100)=15.9$, $\mathrm{p}<.001]$. This change was characterized by a progressive decrease in the ratio of postshock acceleration across trials in the session. A trend analysis indicated that this decrease was almost totally linear 
$[F(1,20)=47.1, p<.001]$. None of the other trend components was significant.

Since changes in the postshock ratio may be due to response rate changes in the baseline, the postshock minute, or both, the response patterns in periods $\mathrm{A}$ and $B$ of the ratio were examined separately. The within-session patterns for these ratio components are shown in Figures 2 and 3, respectively. An anal-

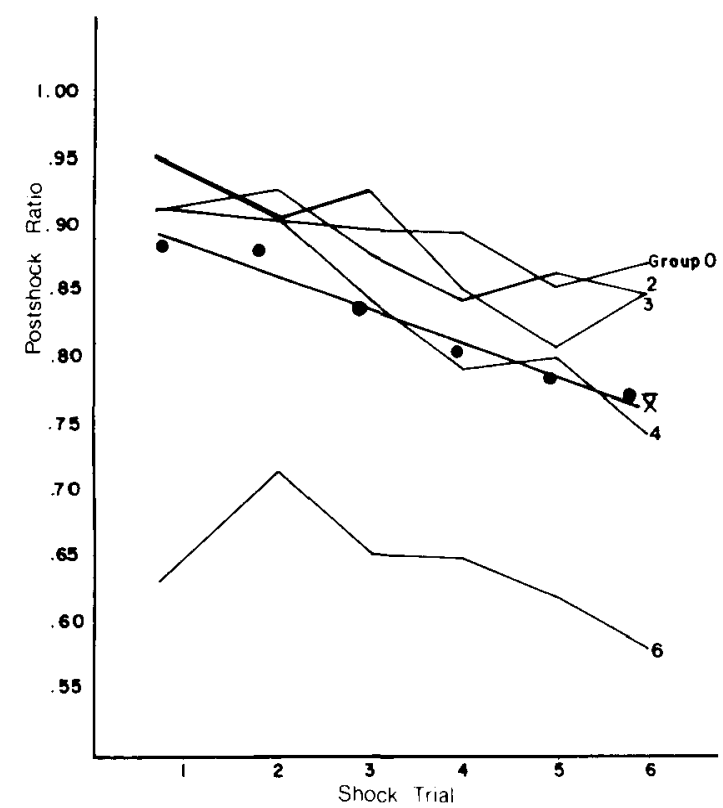

Figure 1. Postshock ratios computed for each of six postshock minutes within the session. The tone-shock contingency was progressively degraded across groups from total reliability (Group 6) to no CS-US relation (Group 0). Mean of five treatment groups is shown by regression line $y=-.022617 x+.90655$.

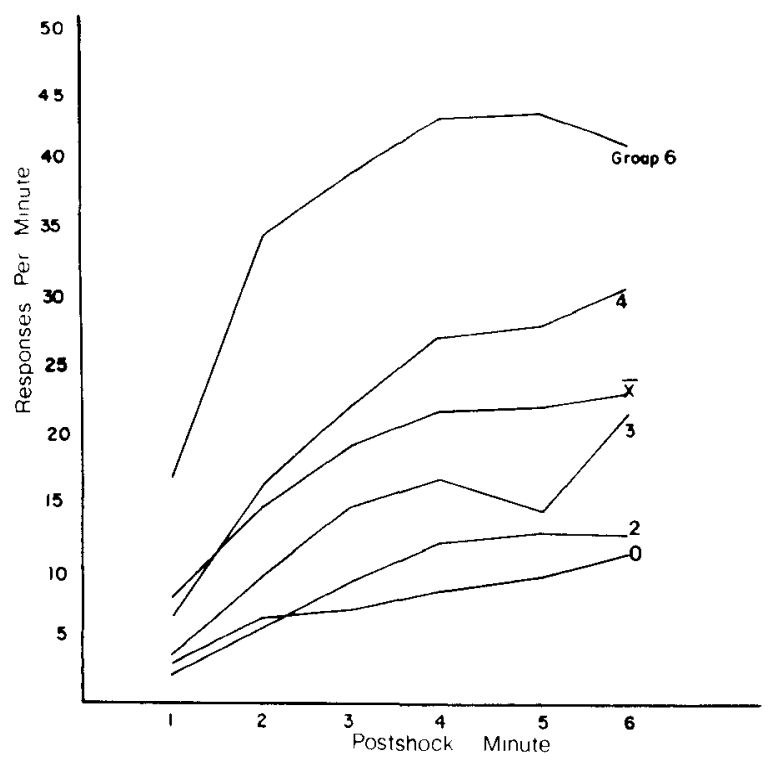

Figure 2. Mean response rate obtained during each of six postshock minutes per session [component $A$ of $A /(A+B)$ postshock ratiol.

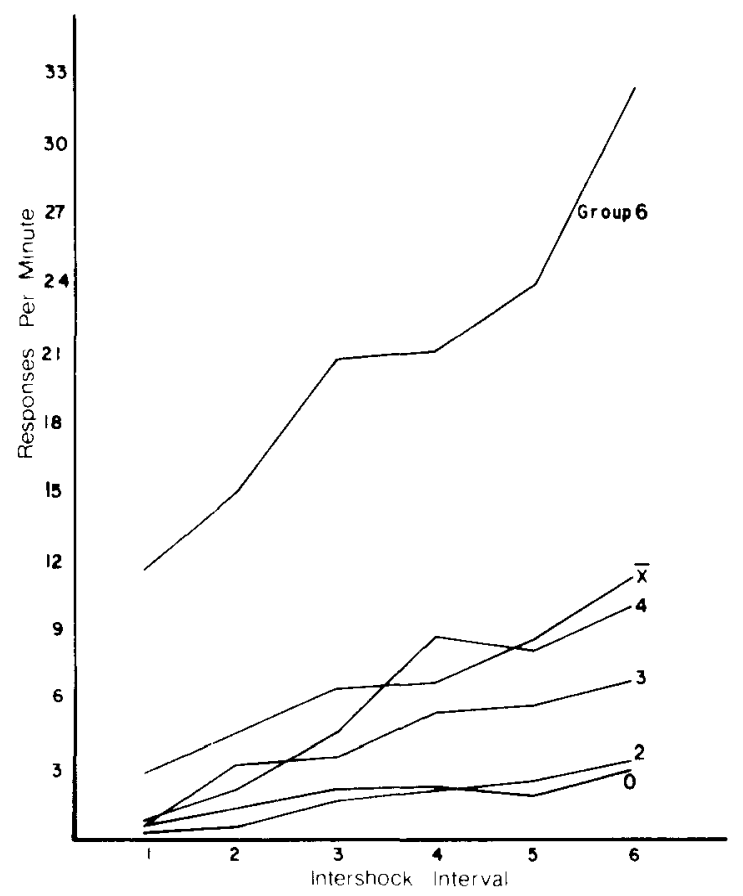

Figure 3. Mean baseline rate obtained during each of six preshock segments of the session [component B of $A /(A+B)$ postshock ratio].

ysis of baseline responding and postshock responding during the final five sessions indicates that the linear change in acceleration ratios within the session was due to corresponding changes in both components of the ratio. Put simply, although baseline and postshock response rates both increased across the session, the baseline rate increased more steadily, thus resulting in the observed decline in autocontingency ratio values.

An analysis of the base-rate data (period B) showed a highly significant change across the session $[F(5,100)=14.1, p<.001]$. A trend analysis indicated that this within-session change was primarily linear $[F(1,20)=16.6, p<.001]$, suggesting that the base rate increased steadily over the session. Similarly, responding during the postshock minute also revealed a significant within-session increase $[F(5,100)$ $=21.8, \mathrm{p}<.001]$. However, the linear increase in postshock responding was not constant and slowed somewhat as the session progressed. This declining acceleration resulted in the session effect's having a quadratic component $[F(1,20)=20.7, p<.001$ (see Figure 3)].

Evidence for ratio autocontingency control. Our previous research (Davis et al., 1975) indicated that following extensive experience with three shocks per session, responding was accelerated following the offset of the third shock. These results suggest that an if-(third)-shock-then-no-(further)-shock autocontingency may also have been effective in controlling baseline responding. Control procedures that varied 
the time of occurrence of the third shock further supported this conclusion.

In the present experiment, each subject received six shocks per session, thereby providing a further opportunity to examine control by what we previously termed a "ratio autocontingency." If such control was in evidence, it would be shown by an accelerated response rate after the last shock, relative to responding during the rest of the session. An examination of the within-session changes in postshock responding (Figure 2) and base rate (Figure 3) revealed no evidence of control by the ratio autocontingency; that is, increases in responding appeared to be uniform over the session.

\section{Discussion}

The present study examined the degree of control exerted by a shock/no-shock autocontingency when the dependability of a simultaneously presented toneshock contingency was systematically degraded. The tone-shock contingency was degraded by increasing $\mathrm{p}(\mathrm{US} / \overline{\mathrm{CS}})$, while $\mathrm{p}(\mathrm{US} / \mathrm{CS})$ remained fixed at 1.00 . The effects of this manipulation were apparent on the conditioned suppression ratio, rate of baseline responding, and conditioned acceleration ratio obtained under the shock/no-shock autocontingency.

The finding that control by the CS deteriorated with the reduction in dependability of the tone-shock contingency is in keeping with a similar outcome reported by Rescorla (1968). However, the current finding that responding during the CS was uniformly low across groups and that CS ratio increases were not necessarily due to response increases during this period, suggests that results such as these should be viewed with caution. For example, Rescorla suggests that CS effectiveness will be reduced whenever $p$ (US/ $\overline{\mathrm{CS}}$ ) is increased. The results reported here indicate that this may not be the case. Changes in suppression ratios probably did not reflect differences in the degree of suppression conditioned to the CS. They were due almost entirely to decreases in base rate, which probably reflect increased conditioning to contextual cues during the non-CS periods of the session. Thus, the only statements that can be made with any confidence concerning the present CS ratio differences are that Group 6 exhibited a low ratio because of a significantly higher base rate, and that there is no evidence of any between-group differences in the rate of responding during the $\mathrm{CS}$ itself. These results underscore the point made by Davis (1981), Davis, Memmott, and Hurwitz (1976), and Seligman (1969), and reflect a growing awareness that the absolute level of baseline responding must be taken into account before ratio values can be meaningfully interpreted.

The effects of increasing $p(U S / \overline{C S})$ were also seen on autocontingency ratios. Again, however, it is im- portant to consider baseline changes in evaluating these effects. The four groups experiencing a degraded tone-shock contingency all had similar autocontingency ratios, which were much higher than the value obtained for the reliable tone-shock group. The collective results for Groups 2, 3, and 4 suggest that any degree of unreliability (as presently defined) introduced into the tone-shock contingency was sufficient to establish maximal autocontingency control, as evidenced by Group 0 . This outcome is most obviously rooted in the base rates, which have direct impact on ratio calculations of autocontingency control, and which were drastically reduced in all groups for which the tone-shock contingency was degraded.

It is appropriate to consider the basis for such extensive baseline reduction, as it appears to be a primary result of degrading the tone-shock contingency. With regard to predicting shock, the tone-shock contingency has two aspects: $\mathrm{p}(\mathrm{US} / \mathrm{CS})$ and $\mathrm{p}(\mathrm{US} / \overline{\mathrm{CS}})$. The first, $p(U S / C S)$, directly underlies conditioned suppression to the CS. Because its probability was fixed at 1.00 in all groups, the degree of response suppression during the CS was uniformly high. On the other hand, $\mathrm{p}(\mathrm{US} / \overline{\mathrm{CS}})$ is that aspect of the contingency that determines the level of baseline responding by specifying the likelihood of shock during non-CS portions of the session. Ordinarily, $\mathrm{p}(\mathrm{US} / \overline{\mathrm{CS}})$ is fixed at 0 in conditioned suppression studies, thus accounting for the relatively high rates of baseline responding typically recorded (Davis, 1968; Davis \& Wright, 1979). In the present case, degrading the tone-shock contingency in Groups 2-4 resulted in increased probabilities for $\mathrm{p}(\mathrm{US} / \overline{\mathrm{CS}})$. In short, non-CS periods were less "safe" for Groups 2-4; associations between shock and contextual cues were formed and baseline responding was suppressed. It is thus possible to account for joint control in Groups 2-4 in terms of the massive baseline suppression produced by higher $\mathrm{p}(\mathrm{US} / \overline{\mathrm{CS}})$ probabilities, although an analysis in terms of reduced redundancy in predicting shock-free periods between the tone-shock and shock/no-shock contingencies is also supported by the data.

The present study thus reemphasizes the fact that the associative effects of shock, or presumably any US, are not necessarily confined to presentations of the CS or post-US minutes. The operational basis for this reasoning is clear. Even the most rudimentary CS-US association implies four relations: $p(U S / C S)$, $\mathrm{p}(\overline{\mathrm{US}} / \mathrm{CS}), \mathrm{p}(\mathrm{US} / \overline{\mathrm{CS}})$, and $\mathrm{p}(\overline{\mathrm{US}} / \overline{\mathrm{CS}})$. The probability of the latter three arrangements might not be specified directly, but their impact on behavior, and on ratio computations, is inevitable.

It is also notable that considerable changes in the rate of responding were recorded within each experimental session. The decline in postshock acceleration, as evidenced by postshock ratios, appears to be 
consistent with previous reports of within-session decrements across a variety of Pavlovian procedures. The findings of Ayres, Berger-Gross, Kohler, Mahoney, and Stone (1979) are perhaps most relevant, since they occurred within a conditioned suppression procedure. These authors reported a similar within-session decline in suppression ratios, which reflect a reduction in fear conditioned to the CS. In the present case, evidence for a reduction in fear within the session stems not only from reduced postshock ratios, but also from the increasing baseline rates upon which the ratios were based. Both our findings and those of Ayres et al. (1979) underscore the fact that even results obtained from individual sessions may be regarded as aggregate data and are capable of obscuring major facets of control exerted by stimulus contingencies.

Perhaps the most unexpected finding in the present experiment is the presence of autocontingency control in Group 6, for which a reliable tone-shock contingency was simultaneously available. This result is in direct conflict with our previous reports that suppressive control by a tone-shock contingency somehow masks or overshadows accelerative control by a shock/no-shock autocontingency (cf. Davis \& MacFadden, 1978; Davis et al., 1975). There are two procedural factors that might account for such discrepant results (see Table 2). One basis for this discrepancy is the fact that six shocks per session were used in the present study, whereas only three USs per session were presented in our earlier experiments. The most likely impact of this procedural difference might be baseline suppression, which would, in turn, affect ratio estimates of control. However, a comparison of the three studies does not reveal a substantial difference in absolute rates of baseline responding. There was some difference, however, in the original baselines and, therefore, the degree to which baselines recovered in each of these studies. Baselines in both the Davis and MacFadden and Davis et al. studies recovered to approximately $50 \%$ of pretreatment rates, whereas Group 6's baseline in the present experiment recovered to only $33 \%$ of initial rate. Although such a difference is worth

Table 2

Summary of Procedural Factors Underlying Discrepant Results of Simultaneous Tone-Shock and Shock/No-Shock Autocontingency Procedures

\begin{tabular}{ccc}
$\begin{array}{c}\text { Number of } \\
\begin{array}{c}\text { CS-US Trials } \\
\text { per Session }\end{array}\end{array}$ & $\begin{array}{c}\text { On the } \\
\text { Baseline }\end{array}$ & $\begin{array}{c}\text { Off the } \\
\text { Baseline }\end{array}$ \\
\hline 3 & $\mathrm{~A}^{*}$ & $\mathrm{~B}$ \\
6 & $\mathrm{C}$ & $\mathrm{D} \uparrow$ \\
\hline
\end{tabular}

*No postshock acceleration to shock/no-shock autocontingency (Davis et al., 1975; Davis \& MacFadden, 1978). tPostshock acceleration to shock/no-shock autocontingency (Davis, Shattuck, \& Wright, 1981, Experiment 1, Group 6). noting, it is not apparent how it might underlie differences in joint control by tone-shock and shock/ no-shock autocontingencies.

Another possible factor is the present use of an off-baseline training procedure, in contrast to the onthe-baseline procedure employed in both the Davis and MacFadden (1978) and Davis et al. (1975) experiments. Again, however, the manner in which offline training might facilitate the appearance of joint tone-shock and autocontingency control is not readily apparent. Regardless of their theoretical significance, both three vs. six trials per session and onvs. off-line training represent logical possibilities, possibilities that were tested in Experiment 2.

\section{EXPERIMENT 2}

Experiment 1 demonstrated that accelerative control by a shock/no-shock autocontingency was indeed possible in the presence of reliably signaled shocks. These results are in direct conflict with our earlier findings, which suggested that control by the autocontingency was somehow precluded by the simultaneous presence of a tone-shock contingency (cf. Davis \& MacFadden, 1978; Davis et al., 1975). Experiment 2 explored this discrepancy by focusing upon the two most obvious procedural differences between Experiment 1 and our previous studies: The number of CS-US trials per session and whether CSUS training occurred on or off the VI baseline. As summarized in Table 2, all four procedural combinations involving three vs. six trials and on- vs. off-line training were run. In so doing, we hoped not only to replicate our earlier findings, but also to identify the operations that were fundamental to generating them.

\section{Method}

Subjects. Twenty-four experimentally naive male Long-Evans hooded rats, about 100 days old, were reduced to approximately $80 \%$ of their free-feeding weights. Deprivation and housing conditions were identical to those in Experiment 1.

Apparatus. Test cages and CS and US parameters were identical to those used in Experiment 1.

Procedure. During Phase 1, all subjects received barpress training on a continuous reinforcement schedule. They were then trained on VI schedules that gradually increased the interval until a stable base rate was obtained on a VI $30-\mathrm{sec}$ schedule. Baseline training was completed in 18 days. All sessions throughout the experiment were $45 \mathrm{~min}$ in length.

At the completion of baseline training, the subjects were matched on their response rates and assigned randomly to one of four groups with six animals per group. During Phase 2, the toneshock and autocontingencies were introduced. As in Experiment 1 , each US was preceded by a CS that lasted for $1 \mathrm{~min}$. The autocontingency consisted of a minimum 3-min intershock interval. Half of the subjects experienced CS-US presentations while "on-line" (with the lever inserted into the test chamber and the VI schedule in effect), whereas the remainder of the subjects were exposed to "off-line" CS-US trials (with the lever retracted and the VI schedule discontinued).

The on- and off-line groups were further divided, with half of the subjects receiving three CS-US trials per session and the remaining subjects experiencing six CS-US trials during each session. 
All off-line subjects received the same number of CS-US exposures prior to being brought on-line in Phase 3. Subjects receiving 3 trials per session (Group 3-off) were run for 16 sessions; subjects receiving 6 trials per session (Group 6-off) were run for 8 sessions. Thus, all off-line subjects were returned to the VI baseline after $48 \mathrm{CS}$-US trials. The off-line groups were brought online by reinserting the lever into the operant chamber and reintroducing the VI 30-sec reinforcement schedule. Phase 3 continued until each group experienced a total of 30 sessions while on-line.

\section{Results}

Base rate. The mean rate of baseline responding for each group during the final five sessions of Phase 3 is shown in Table 3 . Between-session variability in baseline rates was minimal $(<10 \%$ change) during this period. The analysis of group base rates revealed a significant difference during the final five sessions between on-off groups $[F(1,20)=11.68, p<.01]$, but not between Groups 3-6 $[F(1,20)=3.32, p>.05]$.

Conditioned suppression. An $A /(A+B)$ ratio was used to assess suppression during the CS. Because of differences in the format of data collection, "B" consisted of the mean response rate recorded during the 2 min immediately preceding the CS, rather than response rate during the intershock interval, as it had in Experiment 1. "A" consisted of response rate during the 1-min CS. Analyses are based upon mean data for the final five sessions in Phase 3.

Although the on-off treatment produced a difference in conditioned suppression ratios during the initial session of Phase 3 (.16 vs. .02, on vs. off) $[F(1,20)$ $=21.96, \mathrm{p}<.001]$, this difference was no longer evident by the second experimental session $[F(1,20)=$ $3.61, \mathrm{p}>.05]$. Conditioned suppression performance remained stable for the balance of Phase 3, and all groups showed a preshock ratio of either .01 or .02 during the final five sessions (see Table 3 ). As expected, there was no significant difference between treatments [on-off, $\mathrm{F}(1,20)=.23, \mathrm{p}>.25 ; 3-6$, $\mathrm{F}(1,20)=1.81, \mathrm{p}>.1]$.

Shock/no-shock autocontingency. The ratio $\mathrm{A} /(\mathrm{A}+\mathrm{B})$ was used to determine the degree of postshock response acceleration. The number of responses in the minute following shock served as "A," and the same base rate used in calculating preshock ratios served as "B."

The mean postshock ratio for each group during the final five sessions is shown in Table 3. An analysis of the treatments during the last five sessions indi-

Table 3

Group Mean Data Obtained During Final Five Conditioning Sessions of Experiment 2

\begin{tabular}{cccc}
\hline $\begin{array}{c}\text { Treatment } \\
\text { Group }\end{array}$ & $\begin{array}{c}\text { Baseline Responses } \\
\text { per Minute }\end{array}$ & $\begin{array}{c}\text { Preshock } \\
\text { Ratio }\end{array}$ & $\begin{array}{c}\text { Postshock } \\
\text { Ratio }\end{array}$ \\
\hline 3-On & 40.8 & .02 & .525 \\
3-Off & 36.1 & .01 & .562 \\
6-On & 29.7 & .01 & .625 \\
6-Off & 45.2 & .02 & .630 \\
\hline
\end{tabular}

cated a significant difference between the 3-6 treatment groups $[F(1,20)=76.67, p<.001]$. The groups receiving three trials per session had a mean ratio of .54 , whereas the groups receiving six trials per session had a mean postshock ratio of .63 .

The on vs. off baseline training condition had no apparent bearing on autocontingency control. Ratios did not differ during the initial experimental session $[F(1,20)=2.64, p>1]$, the second session $[F(1,20)=$ $2.13, \mathrm{p}>.25]$, or the final five sessions $[F(1,20)=$ $2.66, \mathrm{p}>.10]$. The interaction between 3-6 and on vs. off treatments was not significant $[F(1,20)=2.96$, p > .10].

Relationship between response baseline and autocontingency control. Because estimates of autocontingency control are based upon ratio computations, it is possible that a relationship exists between the magnitude of the base rate and the postshock ratio; in short, higher postshock ratios may be more likely to occur when suppressed baselines occur. To determine if such a relationship existed between baserate and ratio values, we performed a correlation test on individual subject data, regardless of treatment group. Evidence for such a negative relationship was, indeed, found during both the first $(r=-.322, p<.007)$ and second $(\mathrm{r}=-.213, \mathrm{p}<.005)$ sessions. However, not only was this pattern eliminated with continued exposure to the autocontingency, but also, by the final five sessions, a positive correlation was found between the magnitude of postshock ratio and baseline responding $(r=.229, \mathrm{p}<.01)$. In sum, the higher the response rate is, the stronger the evidence for postshock acceleration under the autocontingency.

\section{Discussion}

In Experiment 2, we have examined the two most obvious procedural factors ( 3 vs. 6 trials per session; on- vs. off-line training) to determine why discrepant results have been obtained with autocontingency control in the presence of a tone-shock contingency.

It is worth noting that neither of these variables appears to bear upon the development of conditioned suppression, per se. In fact, a recent survey of procedural differences in the conditioned suppression literature concluded that conditioned suppression has been obtained using both on- and off-line training procedures, and with as few as 1 US per session or as many as 20 (Davis \& Wright, 1979).

The present results strongly suggest that the number of CS-US presentations within a session is the crucial variable to obtaining postshock acceleration in the presence of conditioned suppression. Although all groups evidenced good conditioned suppression, only the treatment groups that received six shocks per session showed accelerative control by the autocontingency. Moreover, this finding was obtained whether or not CS-US training occurred either on or off the VI baseline. 
The relationship between baseline rate and autocontingency control (i.e., conditioned acceleration) has been emphasized in our previous work (Davis et al., 1977; Davis et al., 1976), as well as in the discussion of the results of Experiment 1. Nevertheless, it is unlikely that the difference in autocontingency control between " 3 " and " 6 " groups in the present experiment can be accounted for solely in terms of baseline differences. It is also notable that the similar acceleration ratios recorded for the 6-off conditions in Experiments 1 and 2 were obtained despite more than a twofold difference in base rates (20.4 vs. 53.8 responses $/ \mathrm{min}$ ). Perhaps the most cautious resolution one can reach at this time is that suppressed responding is no doubt helpful in revealing accelerative effects, although suppressed responding is by no means necessary, nor was it even statistically correlated with conditioned acceleration in Experiment 2 . The results of Group 6-off further amplify this point by contesting the notion of a ceiling effect. Mean responding by this group during the postshock minute actually exceeded the baseline rate obtained prior to the introduction of shock.

\section{EXPERIMENT 3}

On the basis of Experiments 1 and 2, it is possible to conclude that simultaneous behavioral control by a tone-shock contingency (conditioned suppression) and a shock/no-shock autocontingency (conditioned acceleration) is possible, providing subjects receive six trials per session. The question remains as to whether the effectiveness of this procedure is tied to six trials per se, or whether the number of trials is crucial only relative to session length. In short, is it the absolute number or the density of trials within a session that determines whether postshock acceleration will occur jointly with conditioned suppression?

The following experiment explores this question by using simultaneous tone-shock and shock/no-shock procedures at different trial-density values. Previous data indicate joint control at six trials per $45 \mathrm{~min}$, but not at three trials per $30 \mathrm{~min}$ or at three trials per $45 \mathrm{~min}$. Assuming that density is the critical variable, it should be possible to extrapolate the previously successful 6/45-min ratio to a different session length (e.g., three trials per $22.5 \mathrm{~min}$ ) and produce joint behavioral control. Similarly, we should fail to demonstrate joint control under density conditions equivalent to our original failures (e.g., six trials per $60 \mathrm{~min}$ ).

\section{Method}

Subjects. Fifteen experimentally naive male Long-Evans hooded rats, approximately 110 days old, were reduced to $80 \%$ of their free-feeding weights. Deprivation and housing conditions were identical to those used in Experiments 1 and 2.

Apparatus. The apparatus was identical to that used in Experiments 1 and 2 .
Procedure. The subjects were initially trained to leverpress for food on a CRF schedule and were gradually introduced to the VI 30 baseline schedule of reinforcement. All response rates were stable on this schedule following 18-20 daily 45-min sessions.

The subjects were matched for base rate and exposed to one of three treatment conditions. All groups $(\mathrm{N}=5)$ received conditioned suppression (tone-shock) and autocontingency (shock/noshock) training on-line. Procedural arrangements and shock parameters were identical to those used in Experiment 2. Groups differed as to the number of conditioning trials per session and session length. Group $3 / 22.5$ received three trials per session, and each session lasted $22.5 \mathrm{~min}$. Group $6 / 60$ received six conditioning trials during each 60 -min session. A further group was run to replicate the less dense $3 / 45$ procedure unsuccessfully employed in Experiment 2, with a higher number of trials per session; Group 6/90 received six conditioning trials per session, each of which lasted $90 \mathrm{~min}$. All groups were run for a total of 35 daily sessions of exposure to the tone-shock and autocontingency procedures. Ratio calculations followed the methods used in Experiment 2.

\section{Results}

Group data from the final five sessions are reported in Table 4 . The result of primary interest is that only the group receiving three conditioning trials per 22.5-min session showed joint control by the tone-shock and shock/no-shock autocontingency. An analysis of variance revealed a significant difference between group postshock ratios $[F(2,12)=4.7$, $\mathrm{p}<.05$ ] attributable to the $3 / 22.5$-min group. In order to determine whether the ratio value .61 , itself, represented significant acceleration from baseline, we compared response rates obtained during postshock minutes in the final five sessions with response rates recorded during " $\mathrm{B}$," the baseline component of the ratio. This analysis revealed a significant difference between components $[t(4)=2.51$, one-tailed $p<.05$ ], indicating effective accelerative control by the autocontingency.

Baseline responding was most suppressed in the $3 / 22.5$-min group $[F(2,12)=4.1, p<.05]$. A NewmanKeuls analysis revealed that baselines did not differ between the 60- and 90-min groups ( $p>.20$ ). Conditioned suppression was evident in all groups, although no treatment differences appeared on this measure.

\section{Discussion}

The results of Experiment 3 confirm that joint control by tone-shock and shock/no-shock contingencies is indeed possible, and strongly suggest that

Table 4

Mean Baseline Response Rates and Preshock and Postshock Ratios Obtained for Groups 3/22.5,6/60, and 6/90 During Final Five Conditioning Sessions in Experiment 3

\begin{tabular}{cccc}
$\begin{array}{c}\text { Treatment } \\
\text { Group }\end{array}$ & $\begin{array}{c}\text { Baseline Responses } \\
\text { per Minute }\end{array}$ & $\begin{array}{c}\text { Preshock } \\
\text { Ratio }\end{array}$ & $\begin{array}{c}\text { Postshock } \\
\text { Ratio }\end{array}$ \\
\hline $3 / 22.5$ & 15.0 & .01 & .61 \\
$6 / 60$ & 29.4 & .03 & .48 \\
$6 / 90$ & 32.3 & .01 & .49 \\
\hline
\end{tabular}


such control depends upon the density of trials within a session. These results, in conjunction with our previous findings, also make it clear that the number of trials, per se, is not the determining factor, insofar as we have now reported both success and failure using three trials per session and using six trials per session.

The manner in which trial density produces its effects remains at issue. Perhaps the simplest explanation is to focus upon the lower response rates obtained in the $3 / 22.5$ group, the only subjects for which accelerative control occurred. Although the coincidence of these two results is obvious, it is unsatisfying to simply attribute higher postshock ratios to the relatively lower baselines. In its most extreme version, this explanation suggests that baseline suppression is, itself, the primary effect of the density manipulation, and that differences in postshock ratios are merely concomitants or artifacts of baseline differences. There are a number of problems with this view. For one, the continuum of trial density manipulations did not result in a corresponding continuum of baseline suppression; that is, Groups $6 / 60$ and $6 / 90$ did not differ. Moreover, a rate of approximately 15 responses/min, while lower than values obtained for Groups $6 / 60$ and $6 / 90$, is not a particularly extreme value. In fact, previous work in our laboratory has produced both lower response baselines that did not yield autocontingency control and considerably higher baselines that have.

Perhaps there is a simpler and more general explanation for why the denser trial condition produced joint behavioral control. A closer examination of our procedure reveals that by holding the minimum intershock interval constant (at $3 \mathrm{~min}$ in the present experiments) while increasing the density of shocks, we have necessarily changed other features of the procedure: both the variability and the mean of the intershock interval distribution have been reduced. What are the consequences of these changes? If we consider related changes involving the use of food reinforcement, it is clear that their impact on behavior may be considerable. For example, movement from variable to fixed interval distributions has direct bearing on the characteristics of behavioral control (e.g., Catania \& Reynolds, 1968; Davis \& Hubbard, 1972), as does reducing the temporal requirement for reinforcement (Ferster \& Skinner, 1957). If manipulations such as these affect appetitively maintained responding, it is not surprising to find that their counterparts within the present aversive control procedure are similarly potent.

There is additional evidence that trial density or US rate may be an important determinant of Pavlovian conditioning. Both Gibbon (1980) and Jenkins (1980) have independently suggested that the CS-US contingency, as defined by Rescorla (1967), may not be as fundamentally related to conditioning as originally believed. Their alternative view suggests that the critical factor underlying Pavlovian control is the ratio of the average time spent waiting for each US in the CS to the overall average waiting time for a US in the experimental setting. This view, termed the relative waiting time (RWT) hypothesis by Jenkins, has recently been applied to the conditioned suppression procedure. In this study, Jenkins and Shattuck (1981) concluded that better conditioned suppression occurs with lower RWT ratios, independently of CS-US contingency.

The RWT hypothesis has direct application to the present situation. Consider, for example, Groups $3 / 22.5$ and $3 / 30$. The higher US density in Group $3 / 22.5$ translates into a $R W T$ ratio of $1: 7.5$, whereas the lower US density $3 / 30$ group has a RWT ratio of 1:10. According to RWT hypothesis, the lower 1:10 ratio constitutes a more favorable conditioning situation. Just as we originally proposed that degrading the CS-US contingency might lead to the joint emergence of autocontingency control, it is also possible that the higher or less ideal RWT ratio for CS control in Group 3/22.5 might similarly result in the appearance of control by the autocontingency. To a large extent, this has been borne out, as evidenced by the results of Experiments 2 and 3 . It is further supported by the comparison of success in Experiment 1 under the $6 / 45$ condition with our failures to produce joint control under the more ideal 3/30 condition (cf. Davis et al., 1975).

\section{GENERAL DISCUSSION}

We have performed three experiments to explore the manner in which joint tone-shock and shock/noshock contingencies control behavior. Unlike our earlier findings, which suggested that joint suppressive and accelerative control was not detectable under these arrangements (Davis \& MacFadden, 1978; Davis et al., 1975), our present results demonstrate that joint control is indeed possible under particular procedural conditions. For example, it is now clear that accelerative control by the shock/no-shock autocontingency may occur jointly with tone-shock suppression if the tone-shock relation is degraded; moreover, joint control may occur under a perfectly reliable tone-shock relation if the density of CS-US trials is greater than in our original procedures.

It is important to stress that our examination of the variables that determine autocontingency control in the present experiments has been restricted to compound test situations in which tone-shock contingencies were simultaneously presented. Although the interactions between tone-shock and shock/no-shock autocontingencies are interesting in their own right, it remains to be seen whether those variables which affect autocontingency control in compound test situations are also potent when the autocontingency 
is presented independently. For example, does a trial density value that permits autocontingency control to emerge in a joint test situation result in even stronger control by the autocontingency when this procedure is presented in isolation? The examination of this, and related parametric questions bearing on which facets of the intershock interval distribution (e.g., minimum value, variability, mean value) are functionally related to autocontingency control, are currently under way.

Finally, it is possible that our present demonstration of joint suppressive and accelerative control is not confined to the simultaneous use of tone-shock and autocontingency procedures. For example, Davis et al. (1976) similarly reported that joint suppressive/ accelerative control was not possible when a CS-USCS compound was superimposed upon a baseline of food-reinforced responding. Although the CS that preceded shock in the CS-US-CS compound exerted suppressive control, there was no indication of acceleration to the second CS, despite the fact that conditioned acceleration was readily obtained when the US-CS component was presented independently. There is a clear parallel between these findings and our failure to demonstrate autocontingency control in the presence of a tone-shock relation. Reconsidering the Davis et al. (1976) findings in light of the present results suggests that our previous negative conclusions about joint control may have been premature. That is, just as we now know that autocontingency control is possible in the presence of a fully reliable tone-shock relation, so may the CSUS-CS compound have been capable of exerting accelerative control, despite the presence of suppression to the initial CS. Should this possibility be borne out using parameters similar to those successfully employed in Experiment 3, it would underscore the fact that the stimulus relations involved in autocontingencies are essentially Pavlovian in nature, and may be understood in terms of, as well as helping us to understand, the normal mechanisms of learning.

\section{REFERENCES}

Ayres, J. J. B., Berger-Gross, P., Kohler, E. A., Mahoney, W. J., \& Stone, S. Some orderly nonmonotonicities in the trial-by-trial acquisition of conditioned suppression. Animal Learning \& Behavior, 1979, 7, 174-180.
Catania, A. C., \& Reynolds, G. S. A quantitative analysis of the responding maintained by interval schedules of reinforcement. Journal of the Experimental Analysis of Behavior, 1968, 11, 327-383.

Davis, H. Conditioned suppression: A survey of the literature. Psychonomic Monograph Supplements, 1968, 2, 283-291.

Davis, H. On the importance of operant baselines in studies of operant-Pavlovian interactions. In C. M. Bradshaw, E. Szabadi, \& C . F. Lowe (Eds.), Quantification of steady-state operant behaviour. Amsterdam: Elsevier Press, 1981.

Davis, H., Herrmann, T., MacFadden, L., \& Ellen, P. Do septal lesions eliminate behavioral control by an autocontingency? Physiological Psychology, 1977, 5, 339-342.

Davis, H., \& HubBard, J. An analysis of superstitious behavior in the rat. Behaviour, 1972, 43, 1-12.

Davis, H., \& MacF ADdEN, L. Is autocontingency control established when a traditional contingency is simultaneously available? Bulletin of the Psychonomic Society, 1978, 11, 387-389.

Davis, H., \& McIntrate, R. Conditioned suppression under positive, negative, and no contingency between conditioned and unconditioned stimuli. Journal of the Experimental Analysis of Behavior, 1969, 12, 633-640.

Davis, H., MemmotT, J., \& Hurwitz, H. M. B. Autocontingencies: A model for subtle behavioral control. Journal of Experimental Psychology: General, 1975, 104, 169-188.

Davis, H., Mem motт, J., \& Hunwitz, H. M. B. Effects of signals preceding and following shock on baseline responding during a conditioned suppression procedure. Journal of the Experimental Analysis of Behavior, 1976, 25, 263-277.

DAvis, H., \& WRIGHT, J. A note on procedural variability in studies of conditioned suppression. Bulletin of the Psychonomic Society, 1979, 14, 149-150.

Estes, W. K., \& Skinner, B. F. Some quantitative properties of anxiety. Journal of Experimental Psychology, 1941, 29, $390-400$.

Ferster, C. B., \& Skinner, B. F. Schedules of reinforcement. Englewood Cliffs, N.J: Prentice-Hall, 1957.

Gibbon, J. The contingency problem in autoshaping. In C. M. Locurto, H. S. Terrace, \& J. Gibbon (Eds.), Autoshaping and conditioning theory. New York: Academic Press, 1980.

HAMmond, L. Increased responding to $\mathrm{CS}^{-}$in differential CER. Psychonomic Science, 1966, 5, 337-338.

Jenkins, H. M. Why autoshaping depends on trial spacing. In C. M. Locurto, H. S. Terrace, \& J. Gibbon (Eds.), Autoshaping and conditioning theory. New York: Academic Press, 1980.

Jenkins, H. M., \& Shatruck, D. Contingency in fear conditioning: A reexamination. Bulletin of the Psychonomic Society, 1981, 17, 159-162.

Rescorla, R. A. Pavlovian conditioning and its proper control procedures. Psychological Review, 1967, 74, 71-80.

RESCORla, R. A. Probability of shock in the presence and absence of CS in fear conditioning. Journal of Comparative and Physiological Psychology, 1968, 66, 1-5.

Seligman, M. E. P. Control group and conditioning: A comment on operationalism. Psychological Review, 1969, 76, 484-491.

(Manuscript received October 7, 1980; revision accepted for publication March 16, 1981.) 